\title{
Contradições no centro tradicional de Goiânia: usos e transformações no espaço da praça cívica e Avenida Goiás ${ }^{1}$
}

\section{Resumo}

Este artigo trata das mudanças de usos e transformações físicas da Praça Cívica e Avenida Goiás, ambas no tradicional centro de Goiânia. Ao longo da história da cidade, esses espaços foram alterando suas funções inicias em decorrência não só do crescimento e expansão de Goiânia, como também do deslocamento da população do centro para outros bairros, da popularização desta área e dos novos cenários da atualidade, marcados pelas desigualdades e contradições. A verticalização da paisagem a partir de 1960, o aumento crescente do número de automóveis, a criação de shoppings centers e as intervenções dos anos 1990 também contribuíram para a consolidação deste quadro. $\mathrm{Na}$ investigação foram realizadas consultas bibliográfica e documental além de um levantamento fotográfico que revelou as alterações dos usos desses espaços.

Palavras-chave: Praças - Goiânia (GO); Planejamento urbano - Goiânia (GO); Avenida Goiás; Centro de Goiânia.
Ivan Oliveira de Grande

Mestrando em Desenvolvimento

e Planejamento Territorial na

Pontifícia Universidade Católica de Goiás; Professor da

Universidade Paulista - UniP Goiânia e do Centro Universitário de Goiás - Uni-Anhanguera. Brasil ivangrande1@hotmail.com

\section{Deusa Maria Rodrigues Boaventura}

Doutora em Arquitetura e Urbanismo pela Universidade de São Paulo - USP; Professora Pontifícia Universidade Católica de Goiás -PUC/GO e da Universidade Estadual de Goiás UEG.

Brasil dmrb@terra.com.br

\footnotetext{
${ }^{1}$ Este artigo é resultado de parte da pesquisa desenvolvida para a dissertação de mestrado de Ivan Oliveira de Grande, sob a orientação da Profa. Dra. Deusa Maria Rodrigues Boaventura.
} 


\title{
Contradictions in Goiânia's traditional downtown: uses and transformations in space of civic square and Goiás
}

\section{Avenue}

\begin{abstract}
This paper discusses the change of uses and the physical transformations of Civic Square and Goiás Avenue, both in the traditional Goiânia's downtown, at Brazil. Throughout the history of Goiânia these spaces were changing their initial function as a result not only of growth and expansion of Goiânia's Downtown, as well as the displacement of the center of population to other neighborhoods, the popularization of this area and today's new scenarios, marked by inequalities and contradictions. Facts such as the verticalization of landscape from 1960, the increasing number of cars, the appearance of shopping centers and urban interventions of the 1990 s also contributed to the consolidation of this framework. Literature and documents have been consulted in this research as well as a photographic survey that revealed the changes of the uses of these spaces.
\end{abstract}

Keywords: Squares - Goiânia (GO); Urban planning Goiânia (GO); Goiás Avenue; Goiânia's downtown.

\section{Para citar este artigo:}

GRANDE, Ivan Oliveira de; BOAVENTURA, Deusa Maria Rodrigues. Contradições no centro tradicional de Goiânia: usos e transformações no espaço da praça cívica e Avenida Goiás. Revista PerCursos.

Florianópolis, v. 16, n.30,p. 74-98. jan./abr. 2015.

DOI: $10.5965 / 1984724616302015074$

http://dx.doi.org/10.5965/1984724616302015074 


\section{Introdução}

Inaugurada em 1935, Goiânia encontra-se em um cenário brasileiro marcado por grandes transformações e novas definições político-econômicas e socioculturais. Foi à época em que Getúlio Vargas, após se deparar com a economia brasileira debilitada, buscou investir na produção nacional reestruturando todo o antigo sistema colonial de comunicação para a distribuição e consumo da produção tais como: a rede de transportes e a distribuição da população concentrada na região sudeste do país.

Goiânia seria o marco dessa nova época. E sob o comando do então médico e governador Pedro Ludovico Teixeira, ela foi construída segundo estratégias respaldadas na problemática da saúde pública da velha capital e no discurso do progresso. Nesta perspectiva, ela seria o oposto da cidade de Goiás, seria a expressão de uma nova vida e tempo que ideologicamente foram disseminados pela Revolução de 1930 (CHAUL, 2001). Assim sendo, a cidade além de desempenhar a função de centro político e administrativo de Goiás, nasceria com o intuito de simbolizar a modernidade, ultrapassando o isolamento social, político, cultural e econômico do estado em relação ao restante do Brasil.

Para a realização desse importante intento, o interventor Pedro Ludovico Teixeira contratou o arquiteto e urbanista Attílio Corrêa Lima que elaborou um plano inicial de cidade a partir de duas correntes urbanísticas distintas: a francesa e a saxônica. Junto ao plano proposto por Attílio Coréia Lima, com claras inspirações em Versalhes, Karlsruhe e Washington, encontram-se ressonâncias das cidades jardins inglesas e das experiências americanas, sintetizadas por Armando Augusto de Godoy, engenheiro e também urbanista que assumiu o controle dos trabalhos de implantação da cidade após o afastamento de Attílio. Ao assumir tais atividades ele não só alterou o traçado do plano inicial, como propôs também um novo desenho para a parte sul da cidade.

No que diz respeito ao contributo de Attílio Corrêa Lima, o desenho da região central de Goiânia se caracteriza por valorização das ruas, dos quarteirões, das praças e monumentos. Ele também se organiza a partir de um traçado radiocêntrico e ortogonal, que privilegia o tráfego de veículos, as áreas de estacionamento e o tratamento especial 
das praças. O ponto de maior destaque da composição é o centro cívico. Ele é o núcleo central de todo o sistema. Nele, se encontram os principais edifícios públicos administrativos tais como o Palácio das Esmeraldas e a Secretaria Geral. Desta mesma praça convergem as três importantes avenidas de Goiânia: a Goiás, a Araguaia e a Tocantins.

A Avenida Goiás, como é atualmente conhecida, teve primeiramente o nome de Avenida Pedro Ludovico e, segundo o Plano proposto por Attílio Corrêa Lima, tinha como uma das suas funções abrigar o centro de negócios e as atividades relacionadas à coordenação da cidade. Além de originar-se na parte administrativa da cidade, ela cortava o centro comercial, fazendo a ligação com a importante Praça da Estação Ferroviária. Nela, localiza-se ainda o antigo Grande Hotel, onde se reunia a então elite goiana para a realização das grandes festas da cidade (SANTANA apud LIMA FILHO, 2007).

A cidade sendo assim concebida com um desenho e lógica espacial que expressava a marca da modernidade e do novo, se distinguiu claramente dos tradicionais traçados das cidades coloniais brasileiras que se apresentam com sistemas de organização que consideravam as sinuosidades naturais dos terrenos e o destaque dos edifícios religiosos. Diferentemente deste tradicional sistema, Attílio Corrêa Lima apresentou um partido que buscava a monumentalidade. Para tanto, ele condicionou o desenho do espaço público à localização dos edifícios administrativos, ao desenho das ruas e à altura dos edifícios, “considerados partes fundamentais da cidade, assumindo pleno significado na valorização de seu desenho" (MANSO, 2001, p. 251). Tudo isto segundo uma concepção que se referenciava nos princípios da tradição clássica francesa, que valorizava a monumentalidade das praças a partir das fachadas uniformes e das amplas perspectivas acentuadas por grandes avenidas.

Em Goiânia, a praça e estas amplas avenidas, como a Avenida Goiás, seriam os palcos de atividades públicas e marcos referenciais das manifestações cívicas desse novo tempo e, portanto, do eminente progresso desejado para Goiás. Mas, nesse espaço, a religiosidade, a tradição local e os antigos usos e costumes da população, ao que parece, não foram considerados. A cidade se ocuparia mais especificamente em atender a almejada modernidade. Diferentemente das históricas praças ocidentais, entendidas 
como local de múltiplos usos, disputas e conflitos, festas e celebrações, repletas de sentido e significados para a população (CASTRO, 2013), em Goiânia, a praça destinou-se mais especificamente a ser o centro cívico e administrativo. Seus idealizadores, ao negarem o passado definiram funções mais restritas a ela, não considerando as diversas movimentações sociais, sobretudo aquelas relacionadas aos tradicionais usos e costumes de uma população oriunda da velha capital.

Assim sendo, o desenho proposto para a cidade, com os seus novos arranjos espaciais se mostrava estranho para uma população que acabava de chegar à nova capital, vinda de um passado de raízes coloniais. A "nova” praça cívica assemelhava-se a um grande cenário que havia sido pensado segundo princípios estético-culturais europeus. Mas, por outro lado, ela era um sinal de uma nova vida de sonho, promessas e oportunidades que o cidadão local ainda não conhecia. Cartazes de propaganda (Figura 1) e alguns jornais de época mostravam essas ideias. O depoimento de Paulo Augusto de Figueiredo, colaborador de um Jornal mineiro que circulava por toda a região, o Lavoura e Comércio, nos mostra como tais ideias circulavam pela cidade. Segundo ele,

[...] Publicava muita matéria sobre o Estado, inclusive matéria oficial, paga do governo. Principalmente sobre Goiânia. E o que tinha na metrópole, remetido por Câmara Filho, era simplesmente fantástico. Falava-se em verdadeiro Eldorado. Era um Brasil desconhecido que estava nascendo no Planalto. Havia ouro e diamantes pelas ruas, a terra dava tudo, os animais eram fabulosos [...]. (MARTINS apud LIMA FILHO, p. 143, 2007)

Pensada dessa forma, a capital de Goiás não seria a guardiã das tradições, mas a vanguardeira da marcha para o Oeste. Apresentando-se em total antagonismo à antiga capital, ela expressava a vontade de um futuro e de uma esperança (SILVA, 2012). 


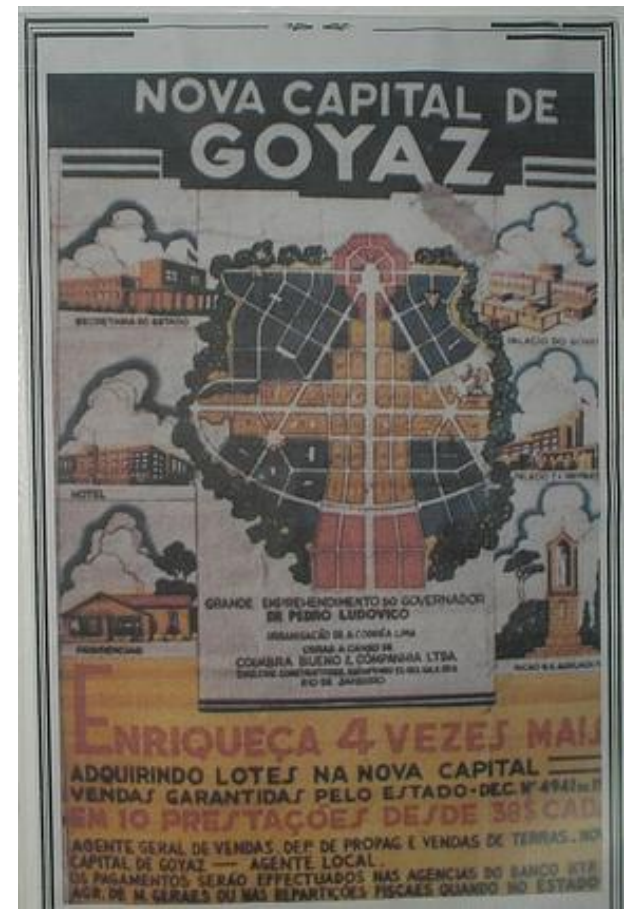

Figura 1 - Cartaz utilizado para a propaganda de vendas de lotes na nova capital de Goiás, em 1934 Fonte: Museu Zoroastro Artiaga.

\section{Os usos no espaço público pioneiro do centro de Goiânia}

Os espaços públicos são partes de fundamental importância no desenvolvimento das cidades. Historicamente eles foram tidos, sobretudo, como lugares das manifestações individuais e coletivas de grande alcance sociocultural.

Em Goiânia, como referido anteriormente, os usos de seus espaços públicos foram adequados segundo os valores da modernidade, sendo a Praça Cívica destinada mais diretamente aos grandes eventos cívicos e a Avenida Goiás à realização dos encontros da população. A dinâmica social da cidade se realizava nestes lugares, como também na Praça do Trabalhador, no Grande Hotel, no Jóquei Clube (Figura 2), no Teatro Goiânia e ainda no Café Central (Figura 3). Todos estes espaços eram bastante emblemáticos da nova realidade moderna, legítimos representantes da história da cidade. 


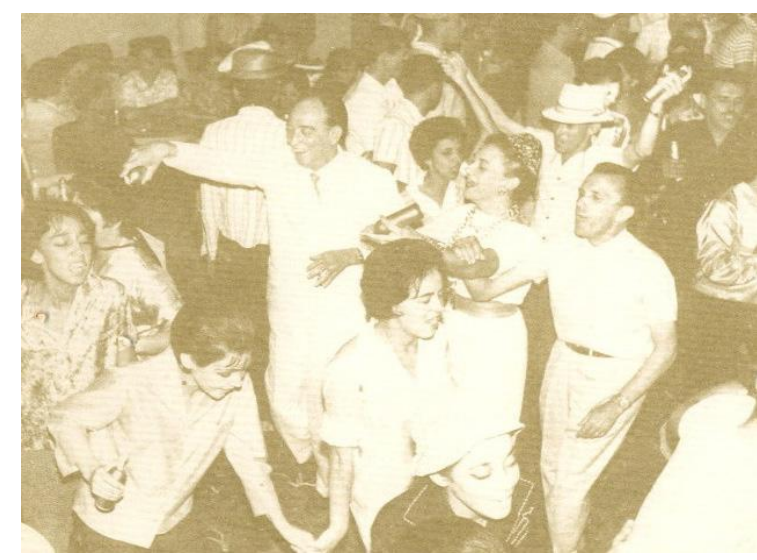

Figura 2- Festa de carnaval com a presença de Ludovico Teixeira. Fonte: Carolina R. Boaventura.

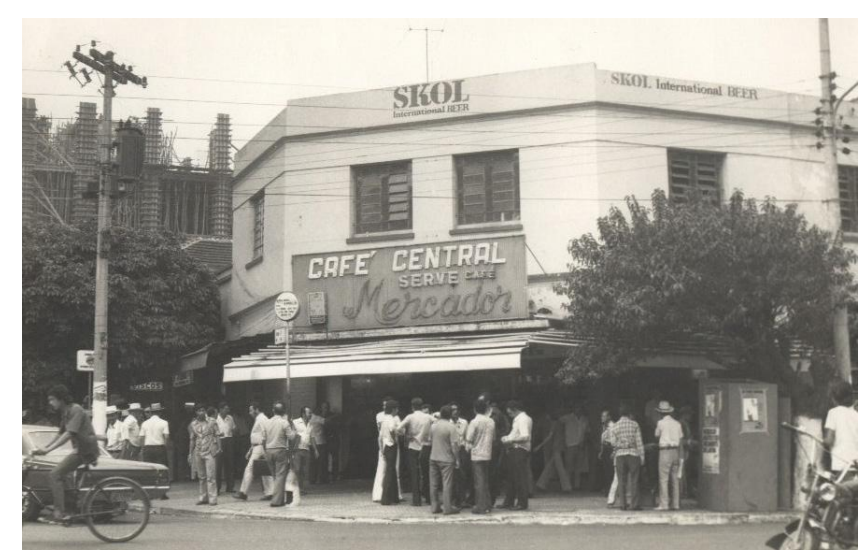

Figura 3- Ponto de encontro no Café Central Pedro na década de 1960. Fonte: Carolina R. Boaventura.

Entretanto, ao longo do tempo, tanto o traçado da Avenida Goiás quanto o da Praça Cívica vêm sofrendo alterações, como também mudanças em seus usos, sejam elas em função dos valores da contemporaneidade, como também pelas intervenções que estes espaços vêm sofrendo. Porém, muitas destas ações estão sempre em busca de inovações, claramente descompromissadas com a história dos lugares.

Tal como acontece em São Paulo, em Goiânia

[...] os habitantes da cidade se defrontam com a situação de a metrópole parece estar destinada a ser sempre nova [...], apagando, com isso, os parcos vestígios do passado, para ser sempre o emblema da modernidade. (GLESSER apud CARLOS, 2007, p.38)

Esse processo de transformação dos usos dos espaços públicos da parte central de Goiânia, bem como a descaracterização de seu plano inicial remonta à década de 1950 quando houve um primeiro momento de expansão da cidade em decorrência das pressões dos especuladores imobiliários, rendendo-se o governo à iniciativa privada (RIBEIRO, 2004).

Exemplo dessas alterações de uso do setor central pode estar associado também coma ocupação do Setor Sul, onde os espaços pensados priorizavam o verde, a intensificação do convício social e a colaboração com uma vida urbana mais equilibrada. Mas, esse processo de crescimento da cidade já era previsto desde 1947. A Figura 2, a 
seguir, indica a presença de um plano de expansão para Goiânia que contribuiu para a descentralização das atividades propostas no traçado pioneiro proposto por Attílio, apresentado anteriormente na figura 1, tais como o Centro Administrativo, a Zona Comercial e a Zona Residencial.

Junto à ocupação do Setor Sul, a criação de novos bairros como o Setor Oeste, o Setor Norte e o Setor Leste (Figura 4), com suas novas dinâmicas, contribuiu com a alteração dos usos públicos da parte tradicional da cidade pois, concomitantemente às formações de tais bairros, ocorreu o deslocamento de diversas atividades do centro para eles.

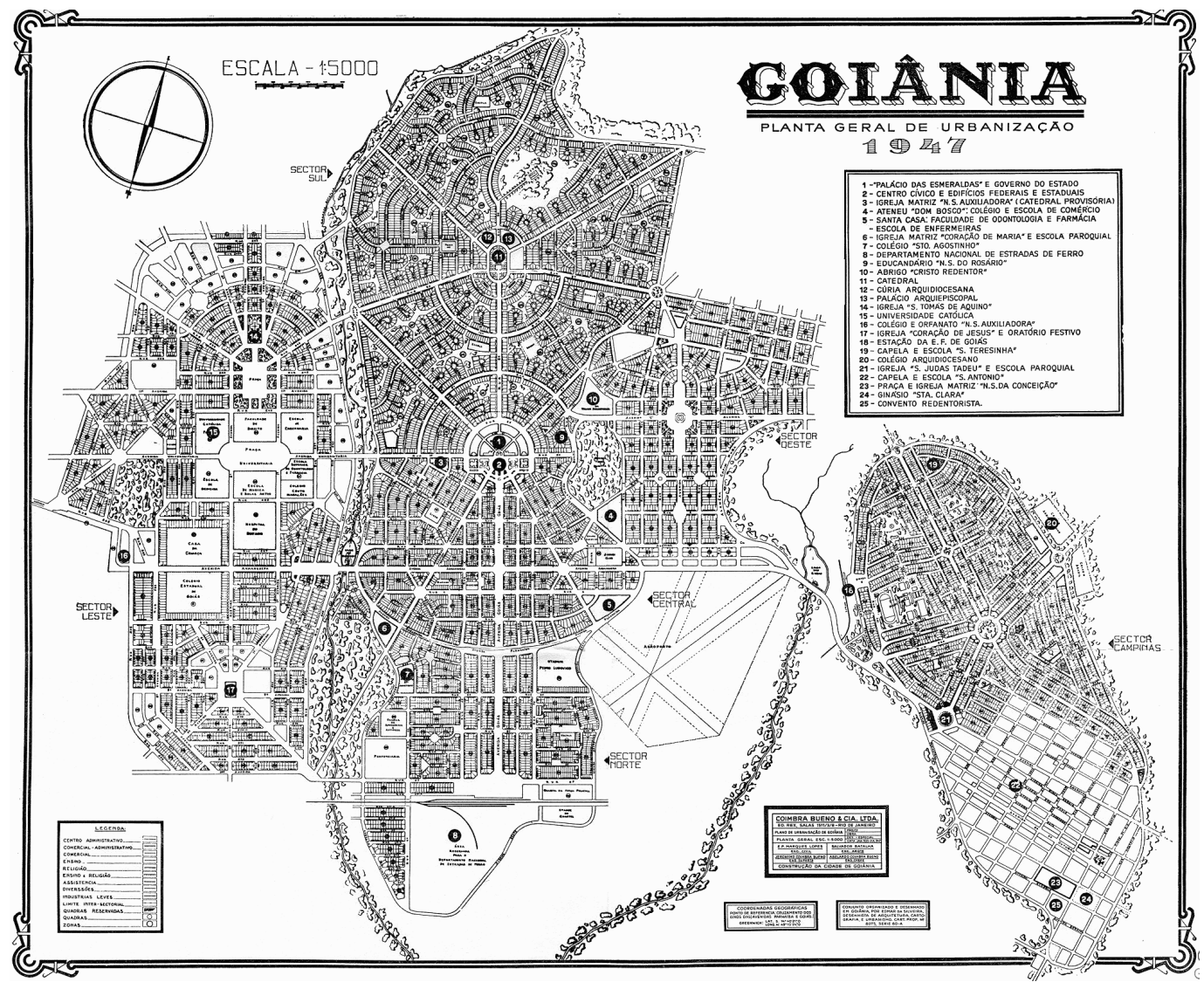

Figura 4 - Planta de urbanização, 1947

Fonte: http://vm136.lib.berkeley.edu/EART/maps/goianix.gif.

A Avenida Goiás, com seu bulevar arborizado, planejada para ser o local de encontro, contemplação e permanência da população e a Praça Cívica, planejada para ser o espaço de manifestações e exercício cívico, esvaziam-se pela transferência de parte da 
população residencial moradora do centro da cidade. A busca pelo novo impulsionava esta população pela procura de novas possibilidades de ocupação e novos estilos de vida nos novos bairros propostos.

A partir dos anos de 1960, Goiânia apresentou o marco do seu primeiro grande crescimento, influenciado principalmente pela imigração dos operários da construção de Brasília. Esse ciclo de crescimento demográfico pós-Brasília e a ausência de loteamentos com infraestrutura urbana para população de baixa renda, fez com a cidade se expandisse e ganhasse 125 bairros $^{2}$ a mais. À medida que a população crescia vertiginosamente, o trânsito goianiense também ganhava o acréscimo de milhares de carros.

Nesse novo contexto, a Praça Cívica e a Avenida Goiás se transformaram ainda mais. Novos usos são vistos nelas como a crescente ocupação do espaço público aberto da praça por automóveis e a inserção de paradas de ônibus do transporte público ao longo da avenida, impedindo o pleno acesso e apropriação pela população. Originalmente, a praça era prioritariamente local de encontros cívicos e de footing passeio informal, caminhada - e era ligada diretamente com a principal avenida da cidade que deveria ser utilizada tal qual uma avenida-parque ${ }^{3}$, como um enorme passeio público (Figura 5). Na conexão entre Praça Cívica e Avenida Goiás, marcos urbanos como o Relógio (Figura 6) e o Coreto, ambos em estilo Art Déco, se faziam presentes como símbolos importantes para a representação da cidade e para a memória urbana. 0 Coreto, edificado acima da cota de nível geral da avenida, era o espaço de encontro e contemplação do conjunto monumental proposto por Attílio. A partir dessa época e aos poucos, estes símbolos passaram a ser menos importantes pelas mudanças de usos no espaço público causadas pela nova dinâmica da capital.

Na década de 1970, as transformações nos usos e espaços do centro são ainda mais expressivas, pois além das diversas atividades comerciais regulares da avenida, a

\footnotetext{
${ }^{2}$ No início de 1980, com a significativa expansão dos loteamentos urbanos, a cidade já tinha em torno de 700 mil habitantes, dos quais 98\% viviam em área urbana (IBGE, 2011).

3 O conjunto apresentava aspecto monumental e pitoresco, com $45 \%$ de sua área ajardinada e convenientemente arborizada.
} 
mudança do seu canteiro central pode ser vista como fator contribuinte para a descaracterização e desimportância do espaço pioneiro.

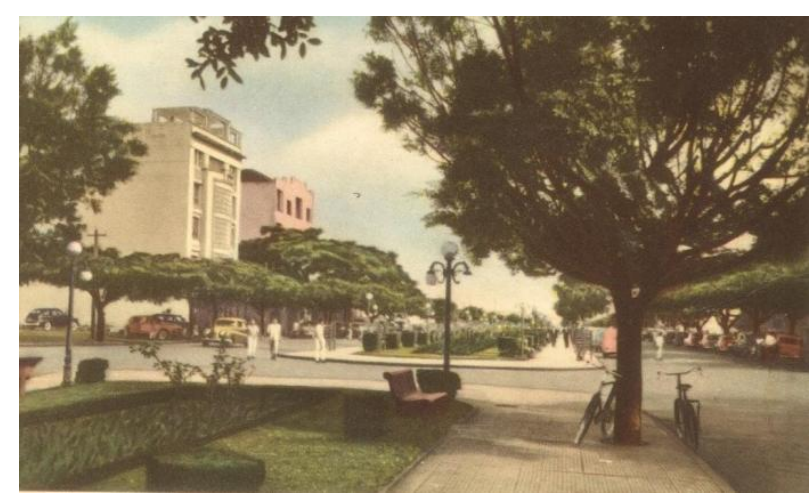

Figura 5 - Avenida Goiás, 1968. Fonte: http://www.skyscrapercity.com/ showthread.php?t=1657128.

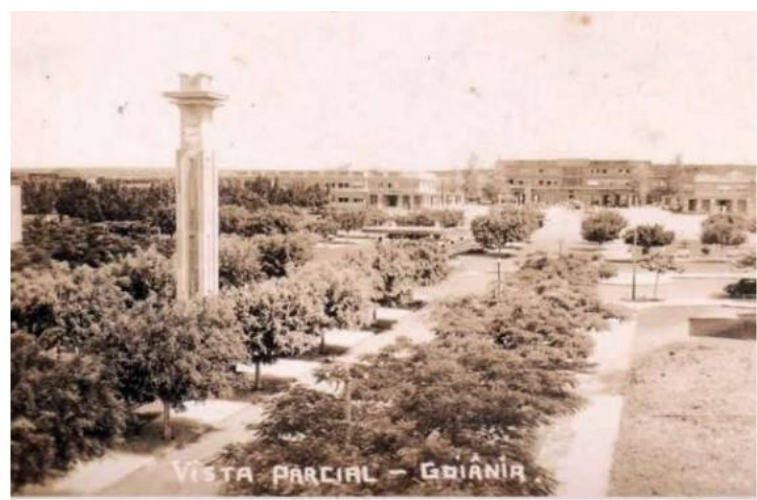

Figura 6 - Avenida Goiás e Relógio, 1942 Fonte: Museu Zoroastro Artiaga.

Um outro fato que também ajuda a compreender tal condição foi o estabelecimento da feira hippie na Avenida Goiás, como pode ser observado a seguir:

[...] a partir dos anos 70, o processo especulativo de ocupação urbana tomou conta de Goiânia, convertendo-a em mais uma cidade brasileira de exclusão social e econômica. O resultado direto desse quadro foi a degradação do espaço urbano, com o comprometimento da qualidade de vida de seus moradores. Essa ocupação irregular dá-se, via de regra, nos vazios urbanos - principalmente no que se refere ao desenvolvimento de atividades econômicas informais - em áreas centrais [...]. Assim, o centro vai gradativamente sendo abandonado pelos moradores e ocupado por prestadores de serviços e comércio. (RIBEIRO, 2007, p. 150)

A feira hippie se localizava inicialmente na área onde hoje se encontra o Parque Mutirama e tinha como principal atrativo produtos artesanais desenvolvidos por hippies. Com a implantação do parque, os feirantes foram transferidos pela administração municipal para a Praça Universitária e, insatisfeitos com o local, decidiram protestar se instalando ao lado Prefeitura e Palácio das Esmeraldas, na Praça Cívica; até o fim da década de 1970, a feira permaneceu neste local. Com o aumento do número de 
vendedores, as barracas passaram a ser montadas pela extensão da Avenida Goiás. Com o passar dos anos, a feira se estabeleceu como força econômica dominante nesse espaço e atingiu a marca de 1000 bancas (CARVALHO, 2007). Ao meio de tantas barracas, a Avenida Goiás originalmente planejada para o encontro e livre circulação passou a ser lócus do comércio. ${ }^{4}$

Quanto à Praça Cívica especificamente, observa-se que suas transformações espaciais e de uso remontam aos anos inicias da implantação da cidade. Nos anos de 1940, se apresentava como um grande espaço aberto e de fácil acessibilidade aos veículos e pedestres (Figura 7). Seu caráter monumental dava destaque ao Palácio das Esmeraldas como principal edifício público frente ao obelisco localizado no centro da praça.

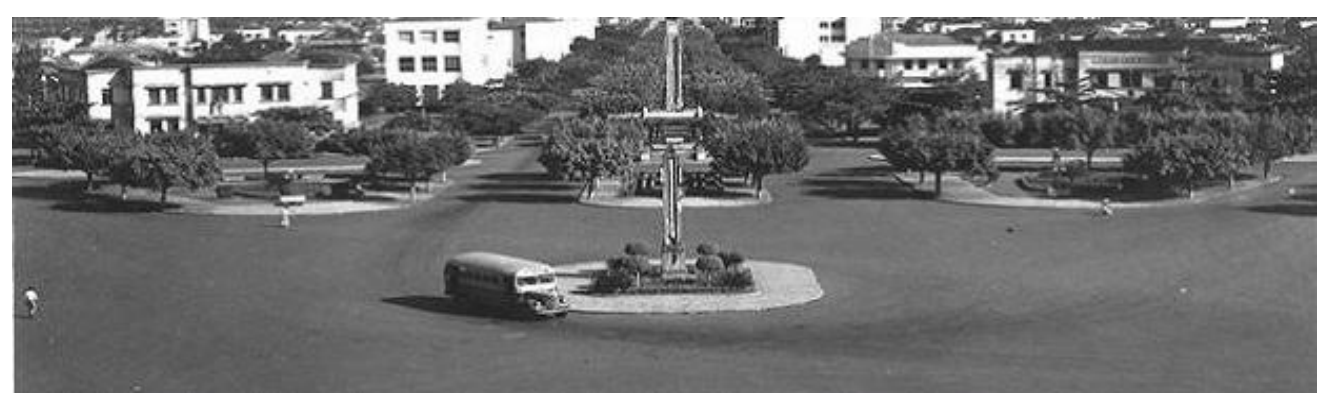

Figura 7. Praça Cívica, 1942. Fonte: Hélio de Oliveira.

Fernandes (2010) afirma que a primeira alteração do traçado original da Praça Cívica foi feita pelo engenheiro Armando Augusto de Godoy. Ao implantar o Setor Sul, Godoy criou também avenidas que convergiam para a parte central do centro administrativo, configurando um sistema em asterisco, no qual a Praça do Cruzeiro seria o novo ponto central. Esta nova organização veio a comprometer a monumentalidade do conjunto cívico. Posteriormente, com o crescente aumento da demanda de serviços relacionados à administração pública decorrente do crescimento vertiginoso da cidade, houve a necessidade da construção “[...] de um anexo, por detrás do Palácio das Esmeraldas, com 12 pavimentos, que funciona como um pano de fundo da praça

\footnotetext{
${ }^{4}$ Da antiga feira de artesanato hippie, somente o nome sobrou. A essa altura a feira já apresentava uma grande diversificação que não remetia mais aos produtos artesanais oferecidos anteriormente; confecções, calçados, produtos importados e alimentos passaram a predominar.
} 
impedindo perspectivas e estando completamente fora de escala" (FERNADES, 2010, p. 12).

No que diz respeito mais diretamente aos usos da Praça Cívica, destaca- se que a partir de 1970, o crescente aumento do número de carros na cidade contribuiu para que ela se transformasse em um grande estacionamento. O pátio interno que anteriormente era destinado à livre circulação de pessoas e eventos cívicos, passou a ficar relativamente comprometido. Foi nessa época também que a praça recebeu a feira livre dos finais de semana. Mas mesmo com esses novos usos a Praça Cívica ainda se manteve resistente às suas funções públicas iniciais, servindo, por exemplo, como espaço para as manifestações de junho de 1983, com grande participação popular a favor do movimento Diretas Já (Figura 8).

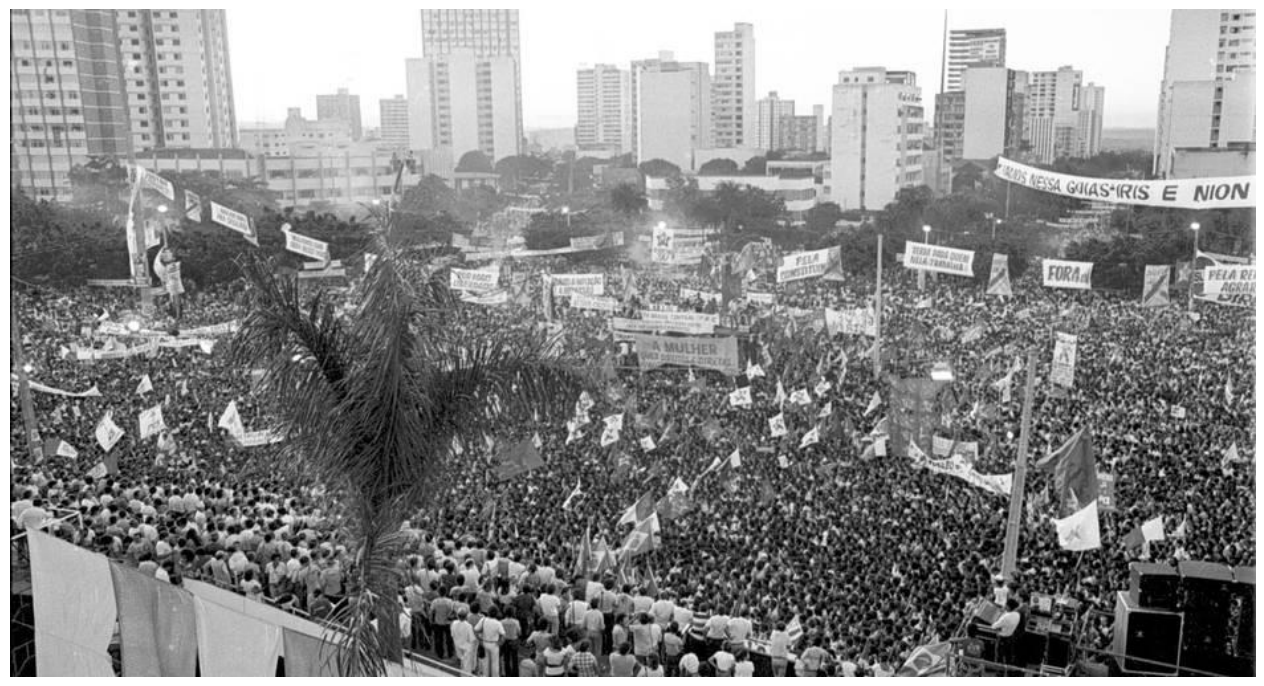

Figura 8 - Comício pelas Diretas Já, Praça Cívica, 1983. Fonte: Hélio de Oliveira.

Nos anos 1980, com a continuidade da expansão comercial iniciada anteriormente, houve o início das contradições no espaço público central. Nessa época, o Setor Central deixou de ser o principal local de escolha residencial, fato que contribuiu para o esvaziamento e declínio dos seus espaços públicos. Novos bairros residenciais como o Setor Oeste e o Setor Sul atraiam as funções de lazer e moradia. Como exemplo de opção de lazer noturno, no Setor Oeste, a Praça Almirante Tamandaré passou a concentrar um 
grande número de bares e restaurantes, que eram frequentados por um grande público que transitava entre estes espaços privados e o espaço público da praça.

Esse era o novo local de ver e de ser visto. Assim sendo, recriava-se, de certo modo, a mesma prática do footing que antes ocorria na Praça Cívica e Avenida Goiás. Além disto, na região Sul da cidade, outra opção de lazer importante que também contribuiu para o esvaziamento das áreas centrais foi a implantação do primeiro Shopping Center do Estado. Em 1981, o Shopping Flamboyant, apresentava todas as comodidades dos grandes centros de compra, nunca antes vista na cidade. Facilidade de acesso de seus estacionamentos, grande concentração de lojas, de salas de cinema e novas opções de alimentação competiam desigualmente na luta entre espaço privado e centro urbano.

Nos anos 1990, a Praça Cívica e a Avenida Goiás já se apresentavam com os problemas urbanos da maioria das áreas centrais urbanas das demais cidades brasileiras. Com sua rotina diária vinculada ao horário comercial, ao cair da noite, os períodos noturnos refletiam a insegurança e o medo nos lugares antes ocupados pelos moradores locais. Parte dos interesses de apropriação por parte da população se deslocou para outras regiões que apresentavam novas opções de entretenimento e lazer liberando a área para a ocupação marginal.

\section{A influência do carro e dos shoppings na transformação dos espaços públicos do centro de Goiânia}

A partir da década de 1990, as contradições observadas no centro de Goiânia se apresentaram crescentes. As novas configurações sociais no espaço urbano agravadas pelo surgimento de novos bairros, pela facilidade de deslocamento através do transporte privado e pela acentuada e crescente procura, por parte da população, por lugares privados dedicados ao consumo como os Shoppings Centers apresentam como possíveis causas do esvaziamento de seus espaços públicos.

Implantado junto à rodovia BR 153, o Shopping Flamboyant (1981) se confirma como uma assustadora construção desconectada da estrutura urbana adjacente. 
Apresenta-se como um enorme obstáculo, com áridos estacionamentos; como se declarasse ao entorno que não faz, e nem quer fazer, parte da cidade. Segundo Maciel (2006)

[...] o mall é a simulação da rua, dirigindo as pessoas de "praça" em "praça": praças que deveriam se firmar com sua excelência no centro urbano. Geralmente com tetos de vidro, sem relógios e com forte iluminação artificial, obliteram a percepção do tempo, distraem para o consumo e forçam os percursos dispondo as "âncoras" atratoras de público - grandes lojas, hipermercados, cinemas, teatros- de tal maneira que forcem o percurso em frente às pequenas lojas, as "satélites". Tanto seu espaço como a lógica de consumo a ele atrelada fazem do shopping uma cidade sem diversidade, exclusiva para quem pode. (MACIEL, 2006, p.10)

Em um âmbito maior, esta condição associa-se aos aspectos da vida pública na contemporaneidade assinalada pela valorização do consumo, do individualismo e da negação do coletivo (SENNETT, 1988). Estes são aspectos que se expressam também no modo de vida do morador de Goiânia e contribuem, por conseguinte, para a redefiniçao e perda da importância das praças e avenidas pioneiras. O relativo abandono desses lugares contribui para o declínio da identidade cívica do tradicional núcleo urbano da cidade, para a desmaterialização e desimportância de seus signos e, consequentemente, de seus significados podendo levar ao comprometimento da memória histórica coletiva.

Barda (2009) reconhece que esse processo pode levar a perdas significativas para os indivíduos, pois, na cidade a sua formação como cidadão

[...] depende de suas origens, antecedentes, educação e regras; quando esses fatores não estão presentes, foram destruídos ou não fazem parte de suas reminiscências (anamnese), o indivíduo perde parte de si mesmo. (BARDA, 2009, p. 24)

Nessa nova dinâmica urbana dos novos tempos, o automóvel também tem um papel especial na transformação do espaço e das transformações no centro de Goiânia. 
Isto porque o sistema automobilístico contribuiu para a modificação e readequação do desenho urbano e as ruas são reestruturadas a favor do transporte individual. Diante de uma nova noção de tempo, os lugares de passagem e de circulação de veículos mudam de significado e passam a ter mais relevância na cidade que os pontos do estar, do morar, do encontro, da festa. Carlos (2007) afirma que na contemporaneidade a paisagem da metrópole é construída e modificada para ser vista em movimento, como alusão à velocidade do mundo contemporâneo, isolando e segregando os espaços antes destinados ao uso público.

A rua tornou-se um resíduo, engrenagem organizativa e mero segmento do plano metropolitano contínuo, no qual os vestígios do passado enfrentam as infraestruturas do novo em uma inquieta situação de impasse. (KOOLHAAS apud. BARDA, 2009, p. 97)

Defendendo a articulação entre os espaços públicos da cidade e a população, em contrapartida à influência segregadora que o automóvel imprime no espaço urbano, Jan Gehl, urbanista dinamarquês, afirma que na contemporaneidade

[...] é o ponto de vista dos motoristas que tem determinado os contornos da maioria das cidades modernas. A escala humana, que eu defendo e aplico, é a que valorize espaços menores, praças e fachadas com detalhes que as pessoas podem observar quando andam a pé. Temos de nos desprender da ideia de que tudo gira em torno dos automóveis.

O que eu defendo é a necessidade de pensar duas vezes antes de construir avenidas e viadutos, que são um estímulo para que as pessoas usem mais e mais carros. Por outro lado, se erguermos praças e ciclovias boas e seguras, estaremos incentivando as pessoas a andar de bicicleta ou mesmo a pé. (GEHL apud JIMENEZ, 2012, p. 20)

O automóvel, como fiel representante do sistema capitalista e como ícone das transformações urbanas do século XX, não só ocupa o espaço e o tempo da sociedade moderna, mas também penetra nas profundezas da vida cotidiana (SCHOR, 1999).

Suas influências podem ser observadas nas "amputações" causadas pela priorização do sistema viário nas praças da cidade. A Praça Latif Sebba localizada no Setor 
Oeste, após intervenção, perdeu seu significado como espaço público de encontro e permanência sendo transformada em marco alegórico, sem significado histórico para a população. Fato que reitera, ao longo da história da cidade, a desconexão entre as necessidades urbanas espaciais e o processo de valorização do patrimônio e da memória da cidade. A antiga Praça Latif Sebba (agora Viaduto Latif Sebba) foi recortada (mutilada, talvez) pelo vazio resultante do rebaixamento da Avenida 85 e é ausente, após intervenção, de espaço público de permanência. Para “coroar” esta modificação da antiga praça, uma escultura ${ }^{5}$ (Figura 9), com proporção fora da escala humana, foi executada em estrutura metálica e simboliza o poder das novas intervenções feitas na cidade a favor da nova mobilidade urbana. Tais quais os novos arranha-céus que, para alguns, simbolizam o avanço da cidade rumo ao moderno, sua locação e dimensão são planejadas apenas para a perspectiva dos que transitam de carro; representam a desconexão do homem a uma cidade que deveria estar tangível a seus moradores.

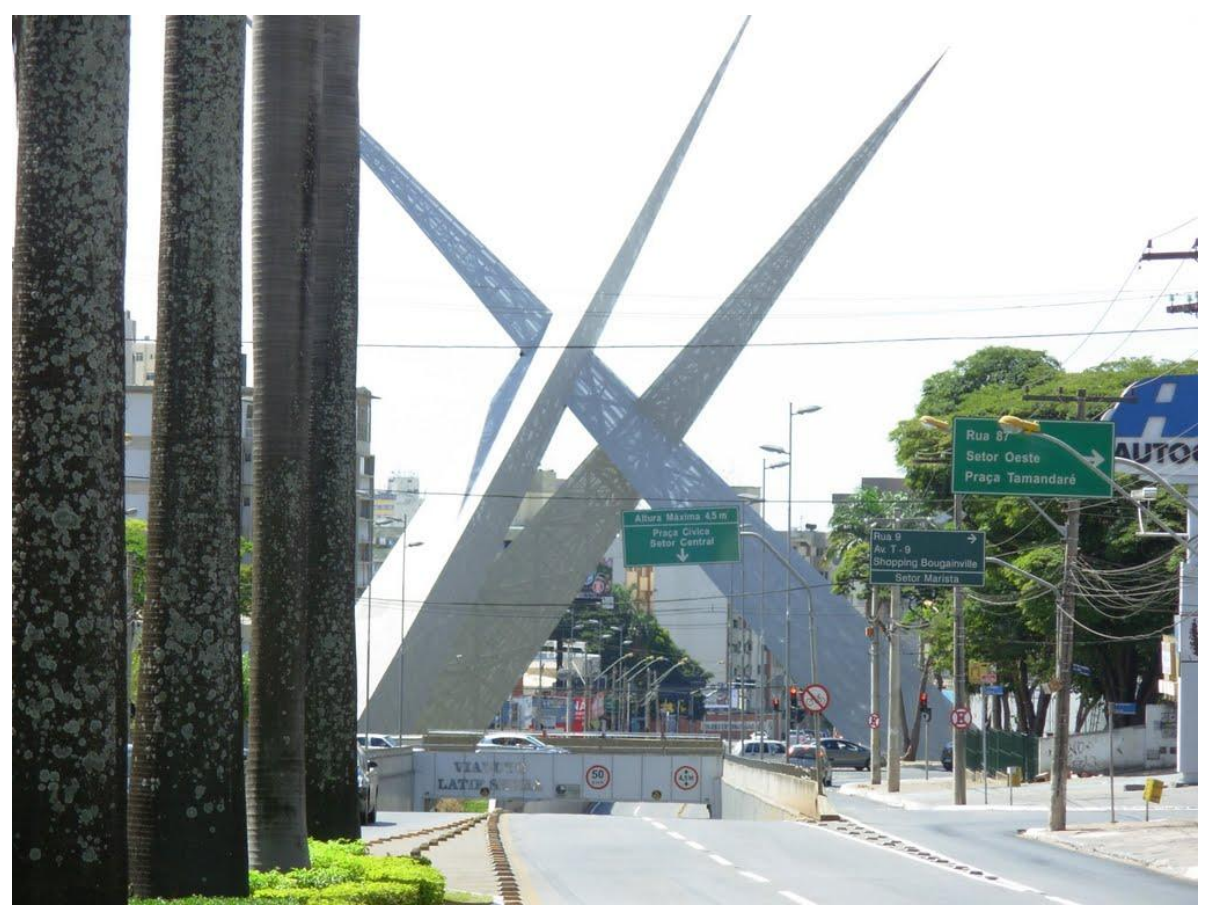

Figura 9 - Praça Latif Sebba e a “mutilação” do espaço público. Fonte: autor.

\footnotetext{
${ }^{5}$ Locada também fora da relação de escala com a própria praça, a escultura foi proposta pelo arquiteto Marco Antônio Amaral que projetou três elementos de 56 metros de altura em forma de lanças. Em intersecção, estes elementos apontam sentidos diferentes - sul, leste e oeste - fazendo referência (de acordo com o partido adotado pelo arquiteto) "às definições de Attílio Corrêa Lima para as direções de expansão da cidade de Goiânia, em 1933” (SILVA, 2012, p. 244).
} 
Decorrente desta nova realidade urbana, em 2001, ações para requalificação da área central começaram a ser tomadas, entre elas a reconfiguração paisagística da Avenida Goiás (2003). Naquele momento, a feira hippie era montada diariamente no canteiro central da avenida, entre a velocidade dos carros, dos ônibus e dos pedestres, reproduzindo um cenário de disputa e conflitos urbanos em área pública de uso deturpado. A ação previa a retirada de todos os ambulantes do bulevar central da avenida e a devolução deste espaço, requalificado, como local de uso público à cidade. Esta proposta ocorreu através de concurso público em que o projeto do arquiteto urbanista Jesus Henrique Cheregatti foi vencedor. Seu projeto teve como diretriz norteadora o resgate das características do traçado pioneiro da cidade, "valorizando as formas Art Déco, presentes em diversos edifícios ao longo da Avenida, ao preservar e ressaltar os monumentos existentes no canteiro central como instrumentos de reabilitação da identidade goiana" (RIBEIRO, 2007, p. 153). Para tal, o bulevar existente no cruzamento da Avenida Goiás com a Avenida Paranaíba sofreu intervenção e nele foi criado o Mercado Aberto que se apresentava como espaço de múltiplo uso possibilitando tanto o funcionamento da feira como de diversas outras atividades de lazer e descanso.

Entretanto, devido ao tamanho restrito da área de sua implantação, o Mercado aberto não solucionou o impasse da locação de tantos comerciantes. Em pressão ao poder público, a associação dos comerciantes da feira hippie de Goiânia, solicitou nova área para a instalação dos ambulantes não contemplados com a locação inicial. O espaço disponibilizado pela administração pública foi a Praça dos Trabalhadores, local da antiga estação ferroviária e cartão postal de Goiânia. Curiosamente, e há mais de 40 anos, este conflito se estende no eixo monumental pioneiro proposto por Attílio. Se iniciou com a ocupação da Praça Cívica como resposta dos ambulantes ao despejo da área anterior à implantação do Parque Mutirama, se estendeu pela Avenida Goiás e se mantém, atualmente, na maior feira livre da América Latina, também ocupando uma praça pública.

Posicionados ao longo da Avenida Goiás, a Praça Cívica, a Praça dos Trabalhadores e o Mercado Aberto são três importantes espaços públicos na cidade e apresentam elementos comuns de ruptura e contradições urbanas. Apesar dos usos regulares em suas atividades comerciais, a realidade noturna revela o conflito social de pessoas 
socialmente excluídas. À noite, estes espaços públicos se tornam o avesso do socialmente aceito. As praças são o local de encontro dos usuários de crack e o Mercado Aberto, dormitório. Entre as estruturas de ferro das barracas que permanecem montadas e debaixo da cobertura têxtil que remete às instalações circenses, o horror da noite entorpece estes usuários que circulam sem dormir, até o retorno da atividade comercial diurna, como presidiários na própria cidade e reféns de sua condição urbana.

Na atualidade, a Avenida Goiás ainda se apresenta como um espaço urbano repleto de contradições. Ao longo do dia, seu bulevar ajardinado se mostra resistente como paisagem congelada de um passado histórico não tão distante mesmo estando ilhado pela velocidade dos fluxos de circulação de ônibus e automóveis e das atividades comerciais do centro da capital. Ao cair da noite, e com a baixa frequentação de moradores locais, a paisagem e os espaços urbanos acolhem os usos da vida urbana dos grandes centros: venda e consumo de drogas, prostituição e abrigo aos moradores em condição de rua.

Muito embora apresente contradições de usos entre os períodos diurno e noturno, a Praça Cívica ainda é o principal local de manifestações públicas da cidade. Em seu espaço cívico é representa a luta ao direito à cidade e à legitimação das diferenças no meio urbano e geralmente serve como ponto de chegada ou partida de passeatas, como as da CUT (Central Única dos Trabalhadores), no dia do trabalho, ou da Parada do Orgulho LGBT (Lésbicas, Gays, Bissexuais e Transexuais). Nos finais de ano, a praça se torna o grande espaço do povo para a comemoração da festa de Réveillon, patrocinada pela administração municipal, com atrações musicais populares e queima de fogos de artifício. Nesse mesmo período, seu pátio interno se transforma em uma vila de natal, com cenários temáticos e quiosques numa grande praça de alimentação. O grande número de ambulantes externos a estes eventos reforça as contradições da cidade contemporânea permitindo uma maior fluidez entre as fronteiras simbólicas que separam as pessoas: nesses momentos de comemoração, a praça nivela socialmente todos que a frequentam.

Fora dos períodos de comemoração ou eventos, a rotina da Praça Cívica se apresenta relacionada aos órgãos públicos nela instalados. Nela, ao se observar a 
importância do automóvel na cidade contemporânea, grande parte da área destinada à permanência e circulação de pedestres transformou-se em estacionamento de veículos que altera o uso efetivo proposto no plano original. O fluxo crescente do tráfego no centro, juntamente com intervenções como a da inserção do eixo de transporte público na atual Avenida Goiás, contribui para sua baixa acessibilidade.

Seu uso "regular" diurno, como grande pátio de estacionamento (Figura 10), se transforma ao cair da noite e, outros agentes urbanos, como os moradores em situação de rua, fazem uso de seus espaços como dormitório e para consumo de entorpecentes. Suas fontes são usadas para higiene pessoal e a falta de iluminação adequada contribui para a sensação de medo e insegurança.

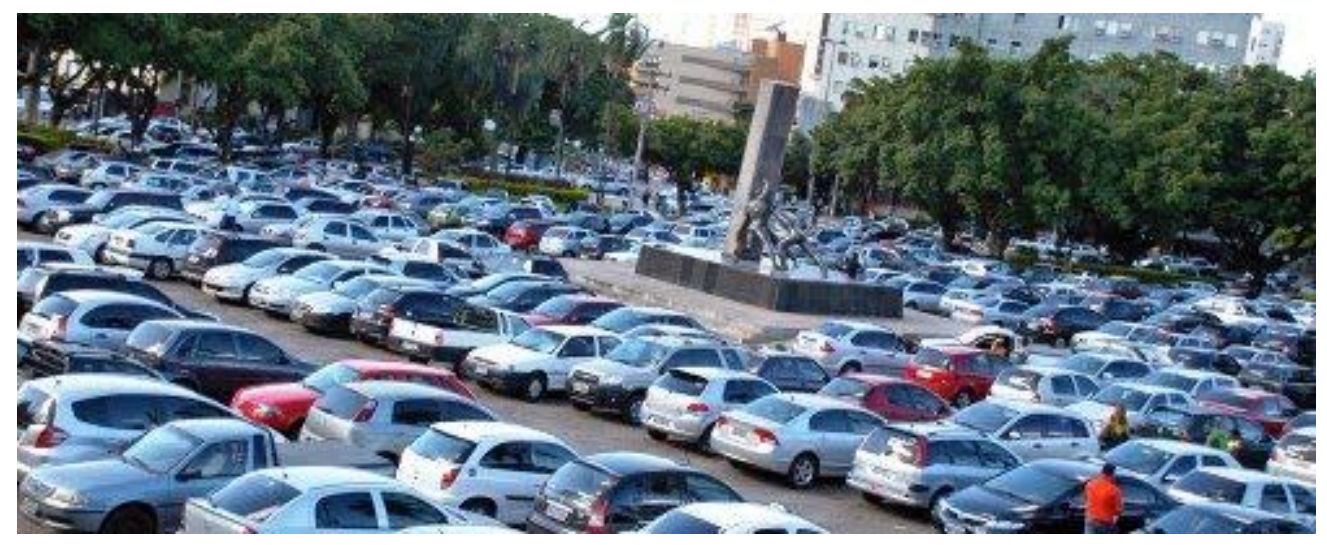

Figura 10 - Praça Cívica e o uso atual do espaço público. Fonte: autor.

No Setor Central, outro espaço urbano relevante que retrata a influência do automóvel na segregação de áreas públicas e na contribuição para as mudanças de uso público é o pátio interno das quadras ou miolo das quadras, com seus acessos feitos através de becos. Valva (2001) afirma que para as quadras da Avenida Anhanguera, principal eixo de transporte leste - oeste, Attílio procurou inovar implantando áreas internas que teriam função pública e serviriam para atender o comércio local, tornando a dinâmica comercial mais eficiente.

Com visão baseada no planejamento higienista, estes espaços serviriam para carga e descarga de mercadoria bem como coleta de lixo, não comprometendo o fluxo da avenida e contribuindo para a higiene e limpeza urbana. Naquele momento, este tipo de 
planejamento que traduzia o zoneamento funcional era o que de mais moderno podia-se pensar para aquela área comercial.

Ainda de acordo com Valva (2001)

Durante as primeiras décadas da cidade, os espaços funcionaram bem como lugar de carga e descarga. [...] Com o grande desenvolvimento comercial ocorrido na cidade depois dos anos 60, esses locais começaram a se degradar. (VALVA, 2001, p. 73)

Ao longo do tempo, com a verticalização da área central e o crescente aumento da quantidade de carros e do volume comercial, os pátios internos às quadras passaram a ser insuficientes, em número e área, para a demanda das atividades comerciais e seu uso original foi deturpado. Como exemplo, a quadra 38 abrigou a Boate Lisita na década de 1970, ilegalmente edificada. Após alguns anos, o DCE da Universidade Federal de Goiás adquiriu o edifício onde encontros e festas de estudantes eram realizados. Segundo Valva (2001, p. 74) "não sobrou nenhum vestígio desse passado, assim como nenhum registro iconográfico", fato que comprova a importância da pesquisa sobre as alterações de usos na cidade como fatores determinantes para a consolidação do passado histórico e memória urbana.

Atualmente, a situação destes espaços é bem diferente da proposta incialmente por Attílio. Invisíveis à dinâmica urbana contemporânea, durante o dia se tornam inacessíveis e labirínticos na malha urbana. Alguns são fechados por comerciantes locais servindo como depósito privado e outros como estacionamento particular. Outros, como o que faz ligação entre Avenida Anhanguera e Rua 3, ao cair da noite, revelam espaços degradados com predomínio de bares e mesas de bilhar ao ar livre, atendendo aos trabalhadores da área central da cidade. Nestes espaços fragmentados do tecido urbano, a insegurança se faz presente, seja pela falta de visibilidade ou de manutenção (Figura 11), sendo comumente utilizados por moradores em situação de rua ou usuários de drogas. 


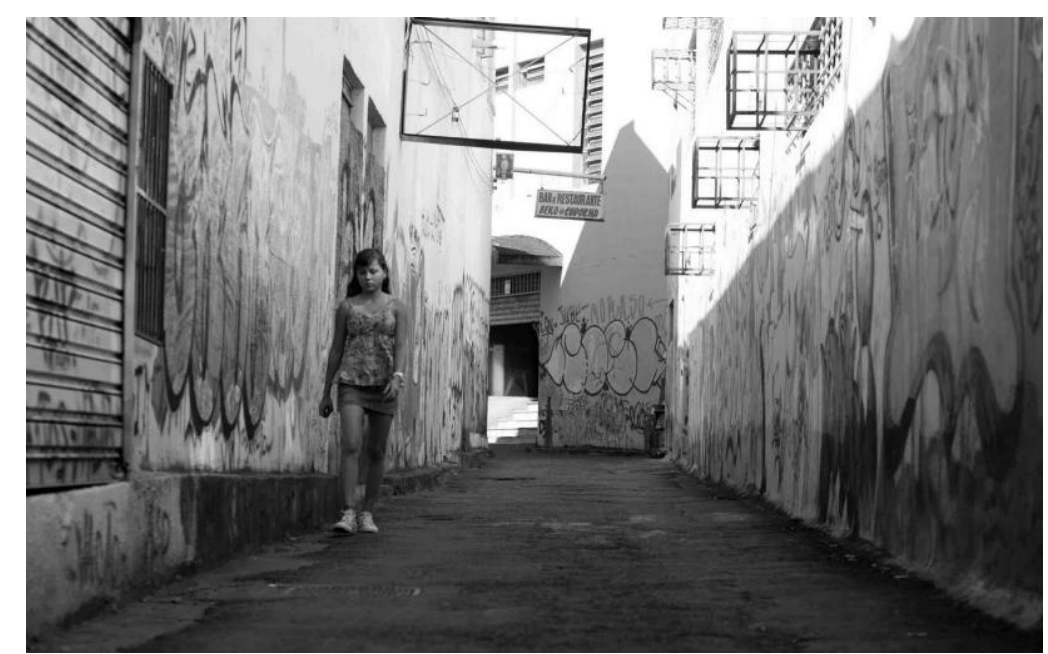

Figura 11 - Acesso ao Beco da Codorna, Goiânia. Fonte: Raphaela Boghi.

As entradas ou passagens que levam aos interiores das quadras são geralmente sujas e abandonadas, despercebidas pela velocidade dos carros ou pela pressa do pedestre que transita pelo passeio público "regular". Estes espaços são como buracosnegros na malha urbana que conectam quem os visita a um tempo lento, diferente do tempo da cidade comum.

O sujeito ali perde suas referências ao percorrer as passagens, encontrase em outros lugares e tempos [...]. Ele está no meio de prédios altos, com suas fachadas lisas, obscuras, que escondem a luz do dia e engolem a solidão da noite. (VALVA, 2001, p. 75)

Em resposta a esta situação observada na cidade, o Conselho de Arquitetura e Urbanismo de Goiás (2014), com o apoio da Prefeitura de Goiânia, lançou em comemoração ao aniversário de 81 anos da capital, sob o tema Ocupa Goiânia: 81 anos, um conjunto de iniciativas culturais que convergiram eventos para a região central da cidade e que tiveram em comum a reflexão e prática da apropriação destes espaços urbanos. Uma das iniciativas foi o “Domingo no Beco". No Beco da Codorna foi montado um palco aberto para apresentações musicais e para livre sarau. O espaço também foi 
destinado a práticas de trocas e comércio livre, bem como apropriação dos muros internos por 60 grafiteiros e suas "artes urbanas".

Apesar da pouca aderência ao movimento por parte da população, provavelmente pela parca divulgação, o movimento deixou algumas marcas através de cores e formas. Nos muros da área degradada do Beco da Codorna, um grafite elaborado pelo artista Wes Gama, chama a atenção por revelar, entre ruínas, uma mensagem contraditória. O painel (Figura 12) intitulado Caipira (2014) revive, no espaço urbano esquecido da cidade, um passado histórico de raízes sertanejas também esquecidas.

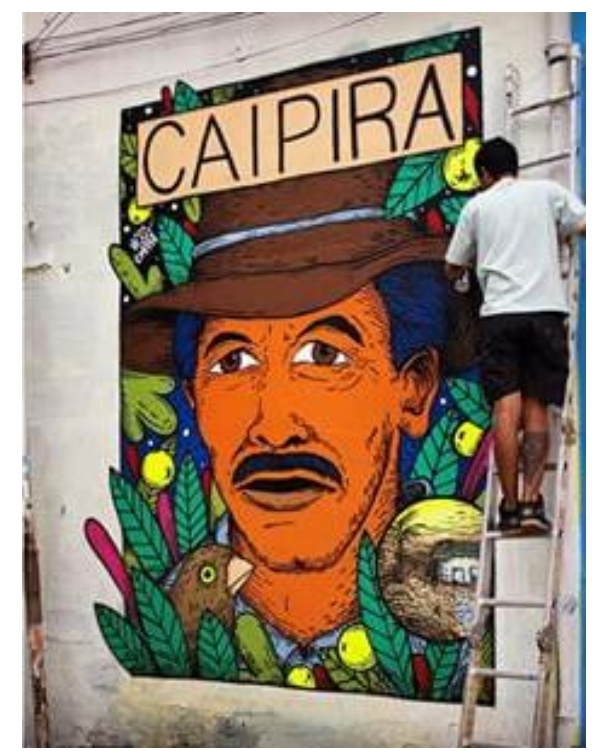

Figura 12. Caipira (2014), de Wes Gama, Beco da Codorna, Goiânia.

Fonte: autor.

A imagem do sertanejo triste reforça as contradições e rupturas de uma cidade ávida pelo novo onde as lembranças dos tempos antigos já não existem mais.

\section{Conclusão}

A realidade da cidade de Goiânia, em especial seu centro pioneiro, é profundamente contraditória, e equívocos no conhecimento de sua história e de sua memória parecem nunca se suavizar na eterna busca da modernidade em uma capital que mostra nunca estar "pronta". Assim, o declínio do espaço público se faz presente: o convívio, a vida coletiva e o encontro, que tradicionalmente aconteciam nos espaços 
públicos do Setor Central passam a acontecer no interior de gigantescos e infinitamente expansíveis centros de compras, os shoppings centers, que derivam de uma cultura de conveniência, tipicamente norte-americana, associada ao uso do automóvel.

Ao longo da história da cidade, através da leitura das praças e das avenidas do Setor Central, observa-se o processo de esvaziamento de seus espaços e crescente distanciamento, por parte da população, dos locais públicos de lazer, contemplação e encontro, incialmente planejados por Attílio Corrêa Lima. Este processo teve origens no surgimento de novos bairros na cidade e, concomitantemente, com a verticalização da paisagem do centro e o crescimento das atividades comerciais, contribuiu para que as áreas destinadas ao uso público fossem substituídas por atividades diversas como feira livre e abrigo para os socialmente excluídos.

As contradições observadas passam também pelo crescimento do número de automóveis da cidade e como ela se reconfigura através de intervenções viárias a favor deste modelo de transporte individual. Acredita-se que tais fatos contribuam para o declínio dos espaços ditos públicos, incentivando a busca, por parte da população, pelos espaços privados alternativos de lazer como Shoppings Centers. Com esta dinâmica percebe-se, portanto, um importante processo de apropriação da área central através de novos agentes sociais.

Se faz imprescindível, contemporaneamente, repensar o espaço público e seu papel na história da cidade, pois o espaço privado se faz cada vez mais privado no acelerado processo de urbanização que produz o que muitos chamam de cenário em ruínas; metáfora que explicita a rápida transmutação e desmaterialização da paisagem dos centros urbanos nos dias atuais. Ao se revisar a memória dos espaços e edificações urbanas, deixa-se de correr o risco de, num futuro próximo, se viver em uma cidade sem história. 


\section{Referências}

BARDA, Marisa. Espaço (meta) vernacular na cidade contemporânea. São Paulo: Perspectiva, 2009.

BOAVENTURA, Carolina Rodrigues. Encontro e memória: o centro de Goiânia e o Jóquei Clube. 2014. 281 f. Monografia (Bacharelado em Arquitetura e Urbanismo) - Faculdade de Arquitetura e Urbanismo - FAU, Universidade de São Paulo, São Paulo, 2014.

CARLOS, Ana Fani Alessandri. O espaço urbano: novos escritos sobre a cidade. São Paulo: FFLCH, 2007.

CARVALHO, Gisélia Lima et al. O impacto da feira hippie no setor turístico-hoteleiro de Goiânia. Boletim Goiano de Geografia, Goiânia: UFG, v. 27, n. 3, 2. sem. 2007.

CASTRO, Luis Guilherme Rivera. O que é espaço público? Revista AU, São Paulo, 232 ed., jul. 2013. Disponível em: <http://au.pini.com.br/arquitetura-urbanismo/232/artigo2920451.aspx>. Acesso em: 19 ago. 2014.

CHAUL, Nasr Nagib Fayad. A construção de Goiânia e a transferência da capital. Goiânia: Ed. UFG, 2001.

CONSELHO DE ARQUITETURA E URBANISMO DE GOIÁS. Ocupa Goiânia, 81anos: atividades culturais: de 11 de outubro a 02 de novembro de 2014 Setor Central, Goiânia, GO. 1 folder. Apoio: Prefeitura de Goiânia: Lei Estadual de Incentivo à Cultura.

FERNANDES, Ludmila Dias. Quatro capitais, quatro praças cívicas. In: SEMINÁRIO DE HISTÓRIA DA CIDADE E DO URBANISMO. Anais eletrônicos... São Paulo, v.11, n. 2, 2010. Disponível em:

<http://unuhospedagem.com.br/revista/rbeur/index.php/shcu/article/view/1318/1292>. Acesso em: 10 ago. 2014.

INSTITUTO BRASILEIRO DE GEOGRAFIA E ESTATÍSTICA (IBGE). Sinopse do senso demográfico 2010. Rio de Janeiro, 2011. Disponível em: < http://www.censo2010.ibge.gov.br/sinopse/index.php?dados=6\&uf=00>. Acesso em: 19 ago. 2014.

JIMENEZ, Gabriele. Tamanho e beleza não são tudo. Revista Veja, São Paulo, v. 2284, p. 17-21, 29 ago. 2012.

LIMA FILHO, Manoel Ferreira e MACHADO, Laís Aparecida (org.). Formas e tempos da cidade. Goiânia: Editora UCG, Cânone Editorial, 2007. 
MACIEL, Carlos Alberto. Shopping Center = Espaço Público? Jornal Hoje em Dia, Belo Horizonte, n.29, out. 2006. Disponível em:

<http://www.arquitetosassociados.arq.br/?artigo=shopping-center-espaco-publico >. Acesso em: 23 ago. 2014.

MANSO, Celina Fernandes Almeida. Goiânia: uma concepção urbana, moderna e contemporânea - um certo olhar. Goiânia: Edição do autor, 2001.

RIBEIRO, Maria Eliana Jubé. Goiânia: os planos, a cidade e o sistema de áreas verdes. Goiânia: Editora UCG, 2004.

RIBEIRO, Maria Eliana Jubé. Paisagem Ambiente. Ensaios...São Paulo, n. 24, p. 147 - 156, 2007. Disponível em: <http://www.revistas.usp.br/paam/article/viewFile/85789/88548>. Acesso em: 24 out. 2014.

SENNETT, Richard. O declínio do homem público: as tiranias da intimidade. São Paulo: Editora Schwarcz, 1988.

SCHOR, Tatiana. O automóvel e o desgaste social. São Paulo em Perspectiva. São Paulo, v. 13, n. 3, 1999 .

SILVA, Clarinda Aparecida. Goiânia (s): representações sociais e identidades. 2012. 331 f. Tese (Doutorado em Geografia) - Programa de Pesquisa e Pós-Graduação em Geografia PPPGG, Universidade Federal de Goiás, Goiânia, 2012.

VALVA, Milena D’Ayla. Paisagens da memória: algumas ruínas em Goiânia. Revista de Arquitetura e Urbanismo da Universidade Estadual de Goiás, Anápolis: UEG, ano I, v. 1, n. 1, 2 sem. 2001.

Recebido em: 08/03/2015 Aprovado em: 28/05/2015

Universidade do Estado de Santa Catarina - UDESC 